\title{
The experience of spasticity after spinal cord injury: perceived characteristics and impact on daily life
}

\author{
William Barry McKay ${ }^{1} \cdot$ William Mark Sweatman $^{1,2} \cdot$ Edelle C. Field-Fote $^{1,3}$
}

Received: 21 June 2017 / Revised: 9 November 2017 / Accepted: 11 November 2017 / Published online: 16 January 2018

(c) International Spinal Cord Society 2018

\begin{abstract}
Study design Cross-sectional survey.

Objectives Determine the impact of motor control characteristics attributed to spasticity, such as spasms, stiffness, and clonus on the daily life of people with spinal cord injury (SCI).

Setting Nationwide, United States.

Methods Internet-administered questionnaire, the Patient Reported Impact of Spasticity Measure (PRISM) and items describing characteristics of spasticity including stiffness, spasms, clonus, and pain.

Results Of the 145 respondents, $113(78 \%)$ reported a PRISM score of at least 5/164, indicating spasticity had some impact on their daily lives. Stiffness impact was highly correlated $(\rho=0.84 ; p<0.01)$ with the PRISM negative impact on Daily Activities subscale and moderately correlated with the other PRISM subscales $(\rho=0.55-0.63 ; p<0.01)$. Spasm presence had a negligible or low correlation with PRISM negative impact subscales $(\rho=0.29-0.47 ; p<0.01)$. Trunk muscle stiffness and spasms had a low correlation with PRISM Need for Assistance and Daily activities $(\rho=0.42$ and $\rho=0.41, p<0.01$, respectively). Anti-spasticity medications were ineffective for $58 \%$ of respondents. Pain in the legs was reported by $57 \%$ of respondents.

Conclusions The experience of spasticity is highly individualized, and is often distributed differently across arms, trunk, and legs. Despite the fact that traditional definitions of spasticity focus on reflex responsiveness, the stiffness associated with spasticity appears to be more problematic than spasms or clonus. The self-described characteristics of spasticity and its physiological presentation are complex and related to pain. This varied presentation lends support to the concept that management of spasticity may be best achieved by multimodality strategies.
\end{abstract}

\section{Introduction}

Each year, 17,000 people are added to the 280,000 who are living with spinal cord injury (SCI) in the United States [1]. Within the first 6-12 months after injury, $70 \%$ develop spasticity [2-4], a form of disrupted motor control more problematic for those with tetraplegia than paraplegia [5]. Spasticity impairs physical activity, emotional, economic, interpersonal, and even cognitive domains of life experience [6]. Spasticity also has a negative impact on quality of life [7]

\footnotetext{
William Barry McKay

barry_mckay@shepherd.org

1 Shepherd Center, Crawford Research Institute, Atlanta, GA, USA

2 Georgia Gwinnett College, Lawrenceville, GA, USA

3 Division of Physical Therapy, Emory University School of Medicine, Atlanta, GA, USA
}

and is associated with early mortality in people with SCI [8]. The evidence clearly indicates that spasticity is a significant issue for persons with SCI [9].

Spasticity as defined by Lance in 1980 is "...velocity dependent, increased resistance to passive stretch as one component of a complex upper motor neuron dysfunction" [10]. The term, spasticity, has also been used to label increased responsiveness to cutaneous input in people with SCI [11]. In fact, SCI-altered motor control produces a variety of signs and symptoms that are associated with spasticity. Further, there is a growing realization that people who seek relief from spasticity experience more than simply excessive responsiveness to peripheral input [4, 12-15]. Pandyan and colleagues [14] advocated for a more inclusive definition of spasticity: “...disordered sensori-motor control, resulting from an upper motoneuron lesion, presenting as intermittent or sustained involuntary 
activation of muscles" to encompass the multifaceted presentation of spasticity.

Comprehensive clinical measurement of spasticity includes an assessment of the impact it has on the daily functioning and quality of life experienced by people with SCI. The Patient Reported Impact of Spasticity Measure (PRISM) [16] is a validated tool that characterizes the ways that spasticity impacts quality of life for people with SCI [17], and provides self-reported, condition-specific measurement of the impact of spasticity on the quality of life [18]. Although such measures offer a way to understand the degree to which spasticity impacts daily life, they do not describe the characteristics of spasticity that people with SCI attribute to limitations in their daily lives and ultimately, overall quality of life.

Severe spasticity appears as "an over-reaction to every kind of input" [19]. As such, reliance on a single measure of spasticity to decide clinical strategies is inadequate [20]. Thus, to fully comprehend how spasticity is experienced, it is necessary to understand the linkage between the impact of spasticity on quality of life and the component characteristics of its complex presentation. Therefore, the main goal of this survey-based study was to understand how people with SCI characterize their experience of spasticity and the relationship between those characteristics of spasticity and perceived impact on daily life. We developed a questionnaire to describe spasticity that included items derived from neurophysiological research. In addition, based on evidence that there may be a relationship between the neurophysiologic mechanisms underlying spasticity and pain, we included items related to the experience of pain in people reporting spasticity. We then sought to identify relationships among characteristics of spasticity and the psychosocial and functional impact these characteristics have on daily life in people who experience spasticity due to SCI.

\section{Methods}

A 75-item questionnaire was posted to an online survey software tool (Survey Monkey: www.surveymonkey.com). The survey included 41 items from the PRISM and 34 items related to characteristics of spasticity. An email invitation was sent to 869 people over the age of 18 with SPI from across the United States who had previously contacted Shepherd Center to express their interest in being involved in research projects.

\section{Patient reported impact of spasticity measure}

The PRISM is a 41-item self-report questionnaire developed and validated for measuring the impact of spasticity on quality of life for persons with SCI [16]. Participants responded to each item with "never true, rarely true, sometimes true, often true or very often true for me." As per published protocol negative impact subscales were scored for social avoidance/anxiety, psychological agitation, daily activities, need for assistance/positioning, need for intervention, and social embarrassment. A positive impact subscale was also scored and subtracted from the subtotal of negative impact subscales to provide a total PRISM score.

\section{Characteristics of spasticity questionnaire}

A 34-item questionnaire comprised of the different characteristics that could be associated with the experience of spasticity was presented ahead of the PRISM items in a continuous series (Table 1). The same five response options employed by the PRISM were used to maintain presentation congruence between the two sets of items. Items for the questionnaire were chosen and worded to describe the qualitative experience of spasticity in terms that were consistent with its neurophysiologic features. For example, spasms were considered in terms of the events that may initiate them, including endogenous events (such as other volitional movements) or exogenous events (such as muscle stretch or tactile input). Stiffness, a term often used by people when describing their experience of spasticity, and items associated with it were included to capture their sense of increased effort needed to initiate and perform volitional movement.

The 34 items in the characteristics of spasticity questionnaire formed from five main subscales: stiffness presence, stiffness impact, spasm presence, endogenously triggered spasms, and exogenously triggered spasms. Items were included to score the experience of trunk muscle spasms, spasms that occur with unknown triggering, and pain. Additional items queried perceived effectiveness of anti-spasticity medication. Due to the survey-based nature of this study, language was chosen to describe the SCI in terms that would be most familiar to the majority of participants. Age, gender, and ASIA grade of injury completeness were not queried.

Respondents provided general demographic information including time since injury onset (6 months to 1 year, 1-2 years, 2-10 years, and greater than 10 years) and neurological level of the lesion (cervical, thoracic, or lumbar), along with information about spasm frequency scored as: [0] no spasms; [1] fewer than 1; [2] 1-5; [3] 6-9; [4] 10 or more spasms per day.

This study was approved by the Shepherd Center Research Review Committee, the local institutional review board for human subject research monitoring. We certify that all applicable institutional and governmental regulations 
Table 1 Characteristics of spasticity questionnaire

\begin{tabular}{|c|c|c|c|c|c|c|c|}
\hline Subscale & $\begin{array}{l}\text { Sequence } \\
\text { number }\end{array}$ & My abnormal muscle control causes... & Never & Rarely & $\begin{array}{l}\text { Some- } \\
\text { times }\end{array}$ & Often & $\begin{array}{l}\text { Very } \\
\text { Often }\end{array}$ \\
\hline \multirow{6}{*}{ Stiffness presence } & 1 & My arms to be stiff & 62 & 10 & 12 & 4 & 12 \\
\hline & 5 & My trunk to be stiff & 27 & 20 & 26 & 15 & 12 \\
\hline & 8 & My legs to be stiff & 8 & 7 & 19 & 27 & 39 \\
\hline & 12 & Feel stiffness in the morning & 11 & 12 & 20 & 21 & 36 \\
\hline & 13 & Feel stiffness in the evening feel stiff all day & 11 & 12 & 20 & 21 & 36 \\
\hline & 33 & Stiffness that goes away when I am asleep & 31 & 25 & 24 & 14 & 6 \\
\hline \multirow[t]{6}{*}{ Stiffness impact } & 14 & $\begin{array}{l}\text { Stiffness that makes it difficult for me to } \\
\text { exercise }\end{array}$ & 21 & 20 & 25 & 19 & 14 \\
\hline & 15 & $\begin{array}{l}\text { Stiffness that makes it difficult for me to feed } \\
\text { myself }\end{array}$ & 73 & 17 & 4 & 3 & 4 \\
\hline & 16 & $\begin{array}{l}\text { Stiffness that makes it difficult for me to get } \\
\text { dressed }\end{array}$ & 39 & 26 & 20 & 8 & 7 \\
\hline & 17 & Stiffness that makes it difficult to breathe & 67 & 18 & 8 & 3 & 4 \\
\hline & 18 & $\begin{array}{l}\text { Stiffness that makes it difficult to perform } \\
\text { hygiene tasks }\end{array}$ & 50 & 24 & 14 & 5 & 6 \\
\hline & 19 & $\begin{array}{l}\text { Stiffness that makes it difficult for me to } \\
\text { operate a wheelchair }\end{array}$ & 45 & 31 & 14 & 6 & 4 \\
\hline \multirow[t]{5}{*}{ Spasm presence } & 2 & My arms to move on their own & 72 & 10 & 9 & 4 & 5 \\
\hline & 6 & My trunk to move on its own & 40 & 19 & 19 & 16 & 7 \\
\hline & 9 & My legs to move on their own & 11 & 4 & 22 & 27 & 35 \\
\hline & 31 & $\begin{array}{l}\text { Movements or spasms that sometimes keep } \\
\text { me from sleeping }\end{array}$ & 24 & 27 & 18 & 19 & 13 \\
\hline & 32 & $\begin{array}{l}\text { Movements or spasms that awaken me from } \\
\text { sleep }\end{array}$ & 26 & 29 & 19 & 14 & 12 \\
\hline \multirow[t]{6}{*}{$\begin{array}{l}\text { Endogenously triggered } \\
\text { spasms }\end{array}$} & 20 & $\begin{array}{l}\text { My arms to move when I take a deep breath, } \\
\text { cough or sneeze }\end{array}$ & 73 & 9 & 10 & 3 & 5 \\
\hline & 23 & Spasms to occur when I move my arms & 61 & 14 & 15 & 6 & 4 \\
\hline & 24 & Spasms to occur when I move my legs & 16 & 12 & 36 & 22 & 14 \\
\hline & 25 & Spasms to occur when I stand & 50 & 12 & 19 & 8 & 12 \\
\hline & 26 & $\begin{array}{l}\text { Spasms to occur when I transfer for one seat } \\
\text { to another }\end{array}$ & 17 & 19 & 30 & 19 & 14 \\
\hline & 29 & Spasms to occur when I am startled & 41 & 17 & 21 & 9 & 12 \\
\hline \multirow{3}{*}{$\begin{array}{l}\text { Exogenously triggered } \\
\text { spasms }\end{array}$} & 22 & Spasms to occur when I am touched & 19 & 11 & 33 & 20 & 17 \\
\hline & 27 & Spasms to occur when others move my legs & 14 & 12 & 27 & 25 & 21 \\
\hline & 28 & $\begin{array}{l}\text { Spasms to occur when my wheelchair or car } \\
\text { hits a bump }\end{array}$ & 32 & 18 & 23 & 14 & 13 \\
\hline Unknown trigger & 30 & $\begin{array}{l}\text { Spasms to occur unexpectedly without any } \\
\text { known triggering event }\end{array}$ & 14 & 13 & 35 & 27 & 11 \\
\hline \multirow[t]{2}{*}{ Clonus } & 3 & My arms to shake (Clonus) & 71 & 8 & 11 & 7 & 4 \\
\hline & 10 & My legs to shake (Clonus) & 12 & 11 & 19 & 29 & 29 \\
\hline \multirow[t]{3}{*}{ Pain } & 4 & Pain in my arms & 65 & 15 & 10 & 7 & 4 \\
\hline & 7 & Pain in my trunk & 41 & 19 & 22 & 10 & 9 \\
\hline & 11 & Pain in my legs & 30 & 13 & 19 & 18 & 20 \\
\hline Spread to trunk & 21 & $\begin{array}{l}\text { Spasms in my arms or legs to activate muscles } \\
\text { in my trunk }\end{array}$ & 35 & 17 & 26 & 14 & 9 \\
\hline Medication Effect & 34 & $\begin{array}{l}\text { Spasticity that is well controlled by } \\
\text { medications I am taking }\end{array}$ & 44 & 13 & 26 & 10 & 7 \\
\hline
\end{tabular}

Five main subscales, two minor subscales and three individual items were acquired from 113 respondents

Item scores in this table are given in percent of total respondents analyzed $(n=113)$. Sequence number is the location in the questionnaire 
concerning the ethical use of human volunteers were followed during the course of this research.

\section{Data analysis}

Data were downloaded from the online survey tool into a spreadsheet (Microsoft Excel; Microsoft Corp, Redmond, WA) and converted to numeric scores ranging from 0 ("never true for me") to 4 ("very often true for me"). Respondents with a PRISM score of $\geq 5$ were included in analysis; these inclusion criteria captured respondents who were experiencing at least a minimal impact of spasticity in their daily lives. These criteria resulted in the exclusion of 16 respondents who reported PRISM scores of $\leq 4$. The data were then exported to statistical analysis software (SPSS 22; SPSS, Inc., Chicago, IL) for analysis. With the goal of detecting a moderate effect size $(d>0.05)$ a statistical power of 0.80 , and an alpha level of 0.05 , sample size calculations $\left(\mathrm{G}^{*}\right.$ Power 3.1.4.) indicated that a minimum of 84 cases would be required to detect a moderate effects size with bivariate correlations and 128 cases to conduct independent means $t$-tests.

Correlations were calculated to determine statistically significant relationships between: (1) PRISM subscale scores (i.e., negative impact [social avoidance/anxiety, psychological agitation, daily activities, need for assistance/positioning, need for intervention, social embarrassment]; positive impact); (2) PRISM subscale scores and total PRISM score; (3) characteristics of spasticity subscale scores (i.e., stiffness presence, stiffness impact, spasm presence, endogenously triggered spasms, exogenously triggered spasms); (4) characteristics of spasticity subscales scores and PRISM subscale scores. Since all ordinal variables were measured on the same Likert response scale, the distance between any two or more responses is essentially the same, and the variables measured similarly important aspects of the same issue, spasticity; some items were summed for analysis. Non-parametric Spearman correlation coefficients were used as the data were based on an ordinal scale from 0 to 4 . Correlation rho $(\rho)$ values were considered very high $(0.90-1.0)$, high $(0.70-0.90)$, moderate $(0.50-0.70)$ or low $(0.30-0.50)$, and negligible $\leq 0.30$ [21]. Independent samples $t$-tests were used to assess betweengroup differences in level of injury, time since onset, spasm frequency, and medication usage. Significance was set at $p \leq$ 0.05 .

\section{Results}

All 145 respondents completed the entire 75 items in the questionnaire (i.e., 34 PRISM items and 41 spasticity characteristics items). The data reported herein was acquired from 113 (78\%) who reported a score of $\geq 5$ on the PRISM, indicating that spasticity had some impact on their quality of life. Of those 113, 60 (53\%) had tetraplegia, $50(44 \%)$ had paraplegia, and $3(3 \%)$ reported injury level as unknown. Time since injury was greater than 2 years for $102(90 \%)$ of respondents, with $<10$ years and $2-10$ years reported by 32 (28\%) and $70(62 \%)$ of respondents, respectively. For those with more recent SCI, time since injury was reported as 1-2 years and 6 months-1 year in $6(5 \%)$ and $2(2 \%)$ of respondents, respectively. This field was unanswered by three respondents. Spasms were experienced on a daily basis by $107(95 \%)$ of respondents, with 10 or more spasm/day being the most often-reported frequency, 50 (44\%) of respondents, and reports of less frequent spasms including 1-5/day by 5 (27\%) and 6-9/day by 27 (24\%). There were no significant differences between respondents with tetraplegia or paraplegia for time since injury or spasm frequency.

\section{Characteristics of spasticity}

Respondents with tetraplegia $(n=60)$ reported stiffness more often than they did spasms in the arms, $63.4 \%$ and $50 \%$, respectively (Table 2). Further, of those with tetraplegia, $21.7 \%$ reported the level of "very often" for stiffness but at only $10 \%$ for spasms. A greater rate of reporting for both stiffness and spasms was found for the trunk, with stiffness reported by $82.7 \%$, and spasms by $68.3 \%$ of those with tetraplegia. Similar to the arms, trunk stiffness was reported as being "very often" by $11.7 \%$ of those with tetraplegia while spasms were reported at that level by 6.7 . For comparing the relative occurrence of stiffness and spasms in the legs, the full set of 113 respondents with spasticity was used. Stiffness and spasms were reported in the legs by 92 and $89.4 \%$ of those 113 respondents, respectively. The maximum score of "very often" was used to describe leg stiffness by $61.1 \%$ and spasms by $64.6 \%$. Thus, in the arms and trunk, stiffness was more prevalent, and was more frequently described as being present "very often", than were spasms; in the legs both stiffness and spasms are equally prevalent.

Respondents with paraplegia reported a significantly greater presence of stiffness $(p<0.01)$, impact on function $(p=0.03)$, and endogenously triggered spasms $(p=0.03)$ than did those with tetraplegia (Table 3). Exogenously triggered spasm presence was similar for both injury-level groups $(p=0.48)$. Those with paraplegia reported significantly more effective medication control over spasticity compared to respondents with tetraplegia $(p=0.03)$.

In the full sample of 113 respondents with spasticity, stiffness was reported to occur "sometimes," "often", or "very often" in the morning in $82 \%$ and persisted throughout the day in $63 \%$ of respondents. Further, $53 \%$ reported that the stiffness disappeared during sleep. In $44 \%$ of respondents, spasms "sometimes," "often", or "very often" kept them from sleeping, and in 38\%, spasms awakened them from sleep. 
Table 2 Characteristics of spasticity subscale values (mean $\pm \mathrm{SD}$ ) for all respondents and divided into subgroups, people with tetraplegia and those with paraplegia
Table 3 PRISM subscale values (mean \pm SD) published by Cook et al. (2007) and values from current data $(n=113)$

\begin{tabular}{lllll}
\hline Characteristics of spasticity subscales & All respondents & Tetraplegic & Paraplegic & $\begin{array}{l}\text { Tetra vs. } \\
\text { para } p \text {-value }\end{array}$ \\
\hline Stiffness presence (0-24) & $11.38 \pm 4.87$ & $12.50 \pm 4.82$ & $9.96 \pm 4.50$ & $\mathbf{0 . 0 0 5}$ \\
Stiffness impact (0-24) & $5.96 \pm 5.46$ & $6.92 \pm 6.19$ & $4.68 \pm 4.10$ & $\mathbf{0 . 0 2 6}$ \\
Spasm presence (0-20) & $7.96 \pm 4.22$ & $8.15 \pm 4.49$ & $7.82 \pm 3.76$ & 0.680 \\
Endogenous triggered spasticity (0-24) & $7.92 \pm 4.81$ & $8.90 \pm 5.05$ & $6.94 \pm 4.21$ & $\mathbf{0 . 0 3 1}$ \\
Exogenous triggered spasticity (0-12) & $5.90 \pm 3.45$ & $6.17 \pm 3.47$ & $5.70 \pm 3.48$ & 0.484 \\
No known trigger (0-4) & $2.07 \pm 1.19$ & $2.08 \pm 1.12$ & $2.12 \pm 1.22$ & 0.870 \\
Clonic spasms (0-8) & $3.19 \pm 1.80$ & $3.43 \pm 2.09$ & $2.84 \pm 1.30$ & 0.072 \\
Trunk muscle involvement in limb spasms (0-4) & $1.46 \pm 1.33$ & $1.58 \pm 1.27$ & $1.36 \pm 1.41$ & 0.384 \\
Pain associated with spasticity (0-12) & $3.81 \pm 2.93$ & $4.00 \pm 3.23$ & $3.60 \pm 2.57$ & 0.480 \\
Spasticity controlled by medication (0-4) & $1.22 \pm 1.30$ & $1.43 \pm 1.42$ & $0.92 \pm 1.05$ & $\mathbf{0 . 0 3 1}$ \\
\hline
\end{tabular}

Note that respondents with tetraplegia reported significantly higher levels of Stiffness Presence, Stiffness Impact, Endogenous Triggered Spasticity and effectiveness of anti-spasticity medications. Bold values emphasize significant statistical difference between tetra- and paraplegic respondents

\begin{tabular}{llllll}
\hline PRISM subscale & $\begin{array}{l}\text { Published } \\
\text { (Cook et al., } \\
\text { 2007) }\end{array}$ & All repondents & Tetraplegic & Paraplegic & $\begin{array}{l}\text { Tetra vs. } \\
\text { para } p \text {-value }\end{array}$ \\
\hline Social avoidance (0-44) & $9.7 \pm 12.1$ & $10.4 \pm 10.0$ & $10.7 \pm 11.0$ & $9.6 \pm 8.6$ & 0.563 \\
Psychological agitation (0-20) & $7.0 \pm 6.1$ & $7.5 \pm 5.4$ & $7.3 \pm 5.6$ & $7.6 \pm 5.2$ & 0.734 \\
Daily activities (0-24)** & $6.5 \pm 5.4$ & $5.5 \pm 5.1$ & $6.4 \pm 5.8$ & $4.4 \pm 3.7$ & $\mathbf{0 . 0 3 7}$ \\
Need for assistance (0-20)* & $4.8 \pm 4.4$ & $5.8 \pm 5.1$ & $7.0 \pm 5.4$ & $4.3 \pm 4.4$ & $\mathbf{0 . 0 0 5}$ \\
Need for intervention (0-20) & $3.6 \pm 4.2$ & $5.5 \pm 4.3$ & $5.6 \pm 4.9$ & $5.4 \pm 3.6$ & 0.818 \\
Social embarassment (0-20) & $4.7 \pm 4.9$ & $4.6 \pm 3.5$ & $4.8 \pm 4.4$ & $4.4 \pm 4.2$ & 0.704 \\
$\quad$ Sub-score (0-148) & & $\mathbf{4 3 . 9} \pm \mathbf{3 0 . 5}$ & $\mathbf{4 6 . 4} \pm \mathbf{3 3 . 3}$ & $\mathbf{4 0 . 1} \pm \mathbf{2 6 . 6}$ & 0.283 \\
Positive impact (subtract)(0-20) & $4.9 \pm 4.0$ & $4.6 \pm 3.5$ & $4.8 \pm 3.6$ & $4.4 \pm 3.3$ & 0.583 \\
$\quad$ Total PRISM score & & $\mathbf{3 9 . 3} \pm \mathbf{2 9 . 3}$ & $\mathbf{4 1 . 7} \pm \mathbf{3 2 . 2}$ & $\mathbf{3 5 . 7} \pm \mathbf{2 5 . 4}$ & 0.283 \\
\hline
\end{tabular}

Also shown are the current data grouped by clinical presentation as people with tetraplegia or paraplegia. Note than $p$-values derived from independent $t$-tests show a significant difference in Daily Activities and Need for Assistance PRISM subscales with people with tetraplegia reporting greater impact than those with paraplegia. Bold values emphasize significant statistical difference between tetra- and paraplegic respondents
Exogenously triggered spasms were reported with greater prevalence than endogenously triggered spasms (Table 1). A substantive majority of respondents reported that both endogenous and exogenous sources triggered their spasms. Five reported only endogenous triggering while two reported only exogenous and three did not respond to either triggering. In addition, $82(73 \%)$ of respondents reported spasms that occurred without recognizable triggering events. Importantly, $74(65 \%)$ of respondents reported that spasms in the legs activated the muscles of their trunks. Pain was reported as occurring at the levels of "sometimes, often or very often" in the arms of $23(20 \%)$, the trunks of $46(41 \%)$, and the legs of $64(57 \%)$ of respondents.

Stiffness and spasm presence were moderately correlated with one another: arms $(\rho=0.63 ; p<0.01)$; trunk $(\rho=0.56 ; p<0.01)$; and legs $(\rho=0.53 ; p<0.01)$. There was a high correlation between endogenously and exogenously triggered spasms $(\rho=0.72 ; p<0.01)$. Correlations between the characteristics of spasticity subscales were only moderate, suggesting that the domains measured were distinct from one another. However, there were no significant correlations between spasticity characteristics and whether or not medication was effective at controlling the spasticity.

\section{Impact of spasticity on quality of life domains (PRISM)}

Respondents reported highest levels of spasticity impact in the Social Avoidance and Psychological Agitation subscales. PRISM Daily Activities and Need for Assistance 
Table 4 Correlations between characteristics of spasticity item groupings and PRISM subscales

\begin{tabular}{lllllll}
\hline & $\begin{array}{l}\text { Daily } \\
\text { activities }\end{array}$ & $\begin{array}{l}\text { Social } \\
\text { embarrassment }\end{array}$ & $\begin{array}{l}\text { Social } \\
\text { avoidance }\end{array}$ & $\begin{array}{l}\text { Psychological } \\
\text { agitation }\end{array}$ & $\begin{array}{l}\text { Need for } \\
\text { assistance }\end{array}$ & $\begin{array}{l}\text { Need for } \\
\text { Intervention }\end{array}$ \\
\hline Stiffness presence & $0.53^{*}$ & $0.47^{* *}$ & $0.35^{*}$ & $0.46^{*}$ & $0.39^{*}$ & $0.34^{*}$ \\
Stiffness impact & $0.84^{*}$ & $0.61^{*}$ & $0.55^{*}$ & $0.63^{*}$ & $0.56^{*}$ & $0.56^{*}$ \\
Spasm presence & $0.47^{*}$ & $0.40^{*}$ & $0.29^{*}$ & $0.47^{*}$ & $0.39^{*}$ & $0.46^{*}$ \\
Endogenous trigger & $0.38^{*}$ & $0.41^{*}$ & $0.24^{*}$ & $0.38^{*}$ & $0.55^{*}$ & $0.33^{*}$ \\
Exogenous trigger & $0.29^{*}$ & $0.42^{*}$ & 0.16 & $0.29^{*}$ & $0.58^{*}$ & $0.28^{*}$ \\
No known trigger & $0.24^{*}$ & 0.17 & 0.17 & $0.24^{*}$ & $0.28^{*}$ & $0.22^{*}$ \\
\hline
\end{tabular}

$\rho$ Spearman's rho

$* p<0.01 ; * * p<0.05$

subscale scores were higher for people with tetraplegia than those with paraplegia (Table 3). There were moderate to high correlations between individual subscale scores and the total score. The highest correlations were found between Psychological Agitation and Need for Intervention $(\rho=0.74 ; p<0.01)$, Psychological Agitation and Social Avoidance $(\rho=0.66 ; \quad p<0.01)$ and Psychological Agitation and Daily Activities subscales $(\rho=0.71 ; p<0.01)$.

\section{Relationships between characteristics of spasticity and PRISM subscales}

Stiffness and spasm presence subscales were moderately correlated with PRISM subscales (Table 4). Stiffness impact was highly correlated with PRISM subscale scores for impact on Daily Activities and moderately with the other subscales and other specific items stating that stiffness interfered with exercise, grooming, dressing, and hygiene tasks; limited capacity for happiness.

Clonus presence had a low correlation with the PRISM Daily Activities subscale $(\rho=0.43 ; p<0.01)$, the Need for Assistance at $(\rho=0.41 ; p<0.01)$ and Need for Intervention at $(\rho=0.40 ; p<0.01)$. The trunk spasm group of items had a low correlation with PRISM Need for Assistance $(\rho=0.42 ; \quad p<0.01)$ and Daily Activities $(\rho=0.41 ; p<0.01)$ subscales. No characteristics of spasticity subscales correlated with the PRISM Positive Impact subscale.

\section{Medication use and effectiveness}

In our sample, $74(65 \%)$ of the respondents indicted they used medications to control spasticity, while $39(35 \%)$ did not use medication. The most often-reported medication used was baclofen, which was used by $55(49 \%)$ of respondents. Medication use was more prevalent in people with cervical lesions. More than one-half of the respondents, $66(58 \%)$, reported that their spasticity was never or rarely controlled by medication.

\section{Pain and spasticity impact on daily life}

Pain had a low correlation with PRISM Social Avoidance $(\rho=0.41 ; p<0.01)$, Daily Activities $(\rho=0.43 ; p<0.01)$, Need for Intervention $(\rho=0.40 ; p<0.01)$, and Social Embarrassment $(\rho=0.40 ; p<0.01)$ subscales. Pain in the arms was moderately correlated with spasm presence $(\rho=0.60 ; p<0.01)$ and with stiffness $(\rho=0.54 ; p<0.01)$. Pain in the trunk correlated moderately with trunk spasm presence $(\rho=0.55 ; p<0.01)$ and stiffness $(\rho=0.43$; $p<0.01)$. Leg pain correlated moderately with trunk pain $(\rho=0.53 ; p<0.01)$ and with spasms that kept respondents from sleeping $(\rho=0.50 ; p<0.01)$, spasms that awaken them from sleep $(\rho=0.45 ; p<0.01)$, and all-day stiffness $(\rho=0.45 ; p<0.01)$. However, pain in the legs showed only a negligible correlation to leg stiffness $(\rho=0.16 ; p<0.08)$ or spasm presence $(\rho=0.16 ; p<0.10)$.

\section{Discussion}

The objective of this study was to understand the characteristics of spasticity that persons with SCI experience as being most prevalent and problematic. Survey items describing the experience of spasticity were drawn from neurophysiology literature describing altered motor control following SCI. The primary finding of this survey study was that stiffness was the characteristic of spasticity that respondents indicated as being most problematic, over and above issues associated with spasms or clonus. Stiffness had a higher prevalence than spasms, and had the greatest negative impact on daily activities and psychological agitation. The perceived experience of stiffness is consistent with neurophysiologic evidence in persons with spasticity, including persistent involuntary motor activity at rest [22], muscle co-contraction during 
voluntary movements [23-27] and spasms triggered endogenously and exogenously. Likewise, in experimental conditions, spasms evoked in response to volitional movement in other body regions [28], hyperactive tonic and phasic muscle stretch [29-31] and cutaneomuscular reflex responsiveness [11] are consistent with spasm activation in daily life. However, while endogenously and exogenously evoked spasms were prevalent in persons with SCI, respondents reported that these influences on daily life were not as problematic as stiffness.

\section{Impact of stiffness and spasms on daily activities and quality of life}

It is increasingly evident that spasticity is complex in its presentation. Although clinically measured as resistance to passive stretch, this is but one aspect of spasticity. Stiffness as reported in the current data was scored as more often present than spasms in the arms and trunk but the same as spasms in the legs. In prior literature, the presence of stiffness in the trunk and legs was reported to be at lower frequency than reported here, 46 and $77 \%$ respectively, in a group of 35 participants with motor-complete SCI [20] and in another study in which roughly $58 \%$ of 26 participants with motorcomplete SCI reported experiencing "stiffness or continuous tension" in the legs [32]. In the current study, the inclusion of both motor-incomplete and complete respondents was likely responsible for the higher reported frequency of stiffness.

\section{Trunk spasticity}

The assessment of trunk muscle paresis or paralysis after SCI has been problematic, leaving clinicians to use sensory level to infer the level and completeness of thoracic lesions [33]. Further, no expert-examiner scale of trunk spasticity has achieved acceptance or common use for SCI. However, neurophysiological characteristics of trunk muscle spasticity have been related to respiratory motor control and impaired respiratory performance [34]. The finding reported herein, that more than $40 \%$ of respondents experience stiffness and spasms in the trunk muscles and that spasms originating in their limbs spread into the trunk, points out that trunk muscle control and spasticity remain poorly understood, unmeasured and unsuccessfully treated.

\section{Pain and spasticity}

Our results suggested that pain and spasticity are related, at least in parallel occurrence if not in shared neural mechanisms. Pain and spasticity have been reported by others to coexist [9] and are among the top four secondary health conditions in people with SCI [35]. In a study of 131 people with upper motor neuron lesions, $80 \%$ believed their pain was related to their spasticity and $62 \%$ reported improvement in pain as a result of botulinum toxin injections that relieved spasticity [36]. Serotonin dysregulation due to long-tract damage has been linked to the development of both pain and spasticity after SCI [37]. In addition, epidural spinal cord stimulation, approved for the treatment of pain [38], is also effective in the treatment of spasticity after SCI [39-42] using similar stimulation parameters. Taking these points altogether, it is not unreasonable to expect that effective treatment for one might be effective in treating at least some aspects of the other.

\section{Neurological injury level}

Respondents with tetraplegia reported a greater negative impact on Daily Activities and Need for Assistance subscales of the PRISM than did those with paraplegia. In addition, stiffness presence and stiffness impact item groupings from the characteristics of spasticity measure were significantly greater in people with tetraplegia than those with paraplegia. This likely reflects the fact that those with impaired arm function need more assistance and experience greater impact of spasticity than those with intact arm control. Further, the problem of spread of spasms to the arms and trunk from the legs reported by respondents with tetraplegia would not occur in those with paraplegia. Thus, the data presented here support the assertion that the characterization of spasticity and its impact on daily life depends on the body region being assessed [20].

\section{Current treatment strategies}

Treatments for spasticity focus on reducing the influence of peripheral inputs or enhancing the effectiveness of central GABA inhibitory neurotransmitter system [43]. Unfortunately, such approaches produce side effects that can include: permanent damage to peripheral nerves; changes in the muscles innervated [44]; unintended degradation of voluntary movement [43, 45]. Consequently, these side effects limit the ability to participate in and respond to neurorehabilitative training [46] and, in the worst cases, cause hepatic and renal organ-system damage [43]. Physical interventions include the use of peripheral afferent input to alter motor neuron excitability via interneuronal circuitry, such as physical stretching [47], neuromuscular electrical stimulation [48], and/or spinal cord stimulation from the epidural space [39-41], or transcutaneously from the surface of the body [49]. Such approaches have not been associated with detrimental effects on motor control or health. More work is needed to develop nonpharmacological approaches to managing spasticity.

Over the past four decades, understanding of spasticity pathophysiology and basic human neuroscientific 
characteristics of spasticity in SCI has grown but only limited changes in treatment strategies have occurred. Perhaps this disconnect is methodological in nature and that those wishing to test clinical treatment strategies have not had the tools needed to verify selective impact on the various physiological markers of disordered motor control at play. In the end, treating the complex spasticity and altered motor control resulting from SCI will likely require highly individualized management of spinal excitatory and inhibitory circuitry using multimodality strategies that will be selected, driven, and tuned by physiological measurement.

\section{Limitations}

A limitation of this study was that although this represents the largest survey in the literature related to the characteristics of spasticity in persons with SCI, the final sample size meets the criteria for achieving a medium effect size for the correlations presented, it is 15 respondents short of the number needed for achieving a medium effect size with our independent samples $t$-tests. However, due to the sample size examined, caution is advised when attempting to generalize these findings to all people with SCI. Further, the number of statistical analyses performed increase the possibility of a type-I error occurring. The absence of age and gender data may limit the comparison of these results to previously published studies and reduce generalizability. Further, it may have been useful to have collected and reported the degree of completeness and a greater resolution of injury level for which we were relying on self-report. However, this data collection was intended to target the relationship between the ways in which people experience the characteristics of motor control that they regard as spasticity and the impact they have on their quality of life. Subscales assembled from the items describing the characteristics of spasticity need further study to establish their sensitivity and reliability. Finally, the scope of this study did not examine the effectiveness of all medications or the broad range of physical interventions currently in use, which are worthy of additional study.

\section{Conclusions}

Individuals with SCI indicated that both the spasms and stiffness associated with spasticity have a significant negative impact on their participation in daily activities and quality of life. While spasms have received considerable attention in the literature, our data suggest that stiffness may be more prevalent and problematic. Moreover, while spasticity of the extremities has received attention, stiffness and spasms of the trunk muscles also have a significant negative impact on daily activities and quality of life. Pain was associated with the presence of spasticity. As may be expected, some characteristics of spasticity were experienced differently depending on whether the respondents had tetraplegia or paraplegia. Finally medications have not been successful in controlling spasticity for a substantial proportion of respondents. More detailed examination and consideration of the stiffness that accompanies spasticity is warranted, both in the clinical and research realms.

Acknowledgements The authors would like to express their gratitude to the respondents who answered our survey and to Leslie VanHiel PT, DScPT for contributions to the questionnaire assembly. The authors are also grateful to Jennifer Iddings, $\mathrm{PhD}$, Steven Estes, $\mathrm{PhD}$, and Cathy Furbish, DPT for their discerning review of the manuscript. Support for this study was provided by the Hulse Spinal Cord Injury Research Endowment.

\section{Compliance with ethical standards}

Conflict of interest The authors declare that they have no conflict of interest.

\section{References}

1. National Spinal Cord Injury Statistical Center. Spinal cord injury facts and figures at a glance 2016. https://www.nscisc.uab.edu/ Public/Facts\%202016.pdf. Accessed on 14 September 2017.

2. Barolat G, Maiman DJ. Spasms in spinal cord injury: a study of 72 subjects. J Am Parapleg Soc. 1987;10:35-9.

3. Maynard FM, Karunas RS, Waring WP. Epidemiology of spasticity following traumatic spinal cord injury. Arch Phys Med Rehabil. 1990;71:566-9.

4. Skold C, Levi R, Seiger A. Spasticity after traumatic spinal cord injury: nature, severity, and location. Arch Phys Med Rehabil. 1999;80:1548-57.

5. Mahoney JS, Engebretson JC, Cook KF, Hart K, Robison-Whelen S, Sherwood AM. Spasticity experience domains in persons with spinal cord injury. Arch Phys Med Rehabil. 2007;88:287-94.

6. Holtz KA, Lipson R, Noonan VK, Kwon BK, Mills PB. Prevalence and effect of problematic spasticity after traumatic spinal cord injury. Arch Phys Med Rehabil. 2017;98:1132-8.

7. Westercam D, Saunders LL, Krause JS. Association of spasticity and life satisfaction after spinal cord injury. Spinal Cord. 2011;49:990-4.

8. Krause JS, Carter RE, Pickelsimer E. Behavioral risk factors of mortality after spinal cord injury. Arch Phys Med Rehabil. 2009;90:95-101.

9. Andresen SR, Biering-Sorensen F, Hagen EM, Nielsen JF, Bach FW, Finnerup NB. Pain spasticity and quality of life in individuals with traumatic spinal cord injury in Denmark. Spinal Cord. 2016;54:973-9.

10. Lance JW. Symposium synopsis. Feldman RG, Young RR, Koella WP, editors. Spasticity: disordered motor control. Chicago, IL: Yearbook Medical; 1980. p. 17-24.

11. Dimitrijevic MR, Nathan PW. Studies of spasticity in man 4, Changes in flexion reflex with repetitive cutaneous stimulation in spinal man. Brain. 1970;93:743-68.

12. Priebe MM, Sherwood AM, Thornby JI, Karas NF, Markowski J. Clinical assessment of spasticity in spinal cord injury: a 
multidimensional problem. Arch Phys Med Rehabil. 1996;77:713-6.

13. Sherwood AM, Graves DE, Priebe MM. Altered motor control and spasticity after spinal cord injury: subjective and objective assessment. J Rehabil Res Dev. 2000;37:41-52.

14. Pandyan AD, Gregoric M, Barnes MP, Wood D, Van Wijck F, Burridge J, et al. Spasticity: clinical perceptions, neurological realities and meaningful measurement. Disabil Rehabil. 2005;27:2-6.

15. Sherwood AM, McKay WB. Assessment of spasticity and upper motor neuron dysfunction. In: Metin Akay, editor. Wiley encyclopedia of biomedical engineering, vol. 5. Hoboken, NJ: John Wiley \& Sons, Inc.; 2006. p. 3306-15.

16. Cook KF, Teal CR, Engebretson JC, Hart K, Mahoney JS, Robison-Whelen S, Sherwood AM. Development and validation of Patient Reported Impact of Spasticity Measure (PRISM). JRRD. 2007;44:363-72.

17. Hill MR, Noonan VK, Sakakibara BM, Miller WC, SCIRE Research Team. Quality of life instruments and definitions in individuals with spinal cord injury: a systematic review. Spinal Cord. 2010;48:438-50.

18. Balioussis C, Hitzig SL, Flett H, Noreau L, Craven BC. Identifying and classifying quality of life tools for assessing spasticity after spinal cord injury. Top Spinal Cord Inj Rehabil. 2014;20:208-24.

19. Nathan PW. Factors affecting spasticity. Int Rehab Med. 1980;2:27-30.

20. Lechner HE, Frotzler A, Eser P. Relationship between self- and clinically rated spasticity in spinal cord injury. Arch Phys Med Rehabil. 2006;87:15-19.

21. Hinkle DE, Wiersma W, Jurs SG. Applied statistics for the behavioral sciences. 5th ed.. Boston, MA: Houghton Miflin; 2003.

22. McKay WB, Ovechkin AV, Vitas TW, Terson De Paleville D, Harkema SJ. Long-lasting involuntary motor activity after spinal cord injury. Spinal Cord. 2011;49:87-93.

23. Dimitrijevic MR. Residual motor function in spinal cord injury. In: Waxman SG, editor. Advances in neurology, vol. 47: functional recovery in neurological disease. New York, NY: Raven Press; 1988. p. 139-55.

24. McKay WB, Verhagen Metman L, Dimitrijevic MM, Sherwood AM, Dimitrijevic MR. Locomotor patterns in humans with impaired spinal cord functions. In: Kraft KG, Shahani B, editors. Motor control disorders, physical medicine and rehabilitation clinics of North America, vol. 4 (4). Philadelphia, USA: W.B. Saunders Co.; 1993. p. 707-30.

25. Maegele M, Müller S, Wernig A, Edgerton VR, Harkema SJ. Recruitment of spinal motor pools during voluntary movements versus stepping after human spinal cord injury. J Neurotrauma. 2002;19:1217-29.

26. Lim HK, Lee DC, McKay WB, Priebe MM, Holmes SA, Sherwood AM. Neurophysiological assessment of lower-limb voluntary control in incomplete spinal cord injury. Spinal Cord. 2005;43:283-90.

27. McKay WB. Neurophysiological characterization of the New Anatomy and motor control that results from neurological injury or disease. Clin Neurol Neurosurg. 2012;114:447-54.

28. Dimitrijevic MR, Dimitrijevic MM, Faganel JF, Sherwood AM. Suprasegmentally induced motor unit activity in paralyzed muscles of patients with established spinal cord injury. Ann Neurol. 1984;16:216-20.

29. Dimitrijevic MR, Nathan PW. Studies of spasticity in man 2. Analysis of stretch reflexes in spasticity. Brain. 1967;90:333-58.

30. Sherwood AM, Dimitrijevic MR, McKay WB. Evidence of subclinical brain influence in clinically complete spinal cord injury: discomplete SCI. J Neurol Sci. 1992;110:90-98.
31. McKay WB, Lim HK, Priebe MM, Stokic DS, Sherwood AM. Clinical neurophysiological assessment of residual motor control in post-spinal cord injury paralysis. Neurorehabil Neural Repair. 2004;18:144-53.

32. Fleuren JF, Voerman GE, Snoek GJ, Nene AV, Rietman JS, Hermens HJ. Perception of lower limb spasticity in patients with spinal cord injury. Spinal Cord. 2009;47:396-400.

33. Kirshblum SC, Waring W, Biering-Sorensen F, Burns SP, Johansen M, Schmidt-Read M, et al. Reference for the 2011 revision of the international standards for neurological classification of spinal cord injury. J Spinal Cord Med. 2011;34:547-54.

34. Ovechkin AV, Vitaz TW, Terson de Paleville D, Aslan S, McKay WB. Evaluation of respiratory muscle activation in chronic spinal cord injury. Res Physiol Neurobiol. 2010;173:171-8.

35. Jorgensen S, Iwarsson S, Lexell J. Secondary health conditions, activity limitations, and life satisfaction in older adults with longterm spinal cord injury. Phys Med Rehabil. 2017;9:356-66.

36. Shaikh A, Phadke CP. Relationship between botulinum toxin, spasticity and pain: a survey of patient perception. Can J Neurol Sci. 2016;42:311-5.

37. Nardone R, Holler Y, Thomschewski A, Holler P, Lochner P, Golaszewski S, et al. Serrotonergic transmission after spinal cord injury. J Neural Transm. 2015;122:279-95.

38. DeRidder D, Vanneste S. Burst and tonic spinal cord stimulation: different and common brain mechanisms. Neuromod. 2016;19:47-59.

39. Dimitrijevic MM, Dimitrijevic MR, Illis LS, Nakajima K, Sharkey PC, Sherwood AM. Spinal cord stimulation for the control of spasticity in patients with chronic spinal cord injury: clinical observations. Cent Nerv Syst Trauma. 1986;3:129-44.

40. Dimitrijevic MR, Illis LS, Nakajima K, Sharkey PC, Sherwood AM. Spinal cord stimulation for the control of spasticity in patients with chronic spinal cord injury: neurophysiologic observations. Cent Nerv Syst Trauma. 1986;3:145-52.

41. Pinter MM, Gerstenbrand F, Dimitrijevic MR. Epidural electrical stimulation of posterior structures of the human spinal cord: 3 Control of spasticity. Spinal Cord. 2000;38:524-31.

42. Dekopov AV, Shabalov VA, Tomsky AA, Hit MV, Salova EM. Chronic spinal cord stimulation in the treatment of cerebral and spinal spasticity. Stereotact Funct Neurosurg. 2015;93: 133-9.

43. Elbasiouny SM, Moroz D, Bakr MM, Mushahwar VK. Management of spasticity after spinal cord injury: current techniques and future directions. Neurorehabil Neural Rep. 2010;24:23-33.

44. Thomas CK, Hager-Ross CK, Klein CS. Effects of baclofen on motor units paralyzed by chronic cervical spinal cord injury. Brain. 2010;133:117-25.

45. Dietz V, Sinnkjaer T. Spasticity. Handb Clin Neurol. 2012;109:197-211.

46. Theriault ER, Huang V, Whiteneck G, Dijkers MP, Harel NY. Antispasmodic medications may be associated with reduced recovery during inpatient rehabilitation after traumatic spinal cord injury. J Spinal Cord Med. 2016; 14:1-9.

47. Nair KPS, Marsden J. The magement of spasticity in adults. BMJ. 2014;349:4737-47.

48. Ho CH, Triolo RJ, Elias AL, Kilgore KL, DiMarco AF, Bogie K, et al. Functional electrical stimulation and spinal cord injury. Phys Med Rehabil Clin N Am. 2014;25:631-9.

49. Hofstoetter US, Krenn M, Danner SM, Hofer C, Kern H, McKay WB, et al. Augmentation of voluntary locomotor activity by transcutaneous spinal cord stimulation in motor-incomplete spinal cord-injured individuals. Artif Organs. 2015;39:E176-186. 